\title{
STUDY OF DEVELOPMENT OF CREATIVITY THROUGH DIGITAL GAMES
}

\author{
Werner W. Marin and Pollyana Notargiacomo \\ Faculty of Computer Science and Technology - Mackenzie Presbyterian University (UPM) \\ Higienópolis Campus - 0132-907 - São Paulo - Brazil
}

\begin{abstract}
The interest in creativity has grown steadily in the last decades. Amidst this surging interest is the question of whether it is possible to aid the development of creativity. This study investigates the possibility of developing a digital game with just such objective. Therefore the game Luovus was created, utilizing previous research on the subject of creativity and digital games as learning aids. The game has been tested with a group of users and seems to be an effect on the player's self perceived creative capabilities and society's impact on their creativity.
\end{abstract}

\section{KEYWORDS}

Creativity, Digital, Games, Development, Test

\section{INTRODUCTION}

Although studies on creativity have been ongoing since 1950 by Maslow (1943) and others, this area has been given increasing importance, not only in the context of individual life, but also the benefits it brings to society (Alencar 2010). With this came the desire to find ways to develop and improve creative thought. Past studies show this is not a fruitless endeavor and that it is indeed possible to develop and individual's creative thought. In an experiment conducted by Azevedo et al. (2017) a group of teenagers showed significant progress after going through the Future Problem Solving program, for instance.

As comprehension of the subject grew, came a search for tools to aid in the development of creative thought. Some experiments studied workplace activities (Wang 2013) and pedagogical activities with children (Coppi 2015).

Following this path, this research proposes to study the viability of developing creative thought through digital games. Prior studies corroborate the supposition that this is possible. FLIGBY, a serious game studied in the research of Buzady (2017) has shown itself successful in inducing the state of flow in the player, this state being important to incentivise creative thought.

To reach the goals of this research, the game Luovus was developed in parallel. Luovus will be further elaborated on in the Method section of this paper.

\section{LITERATURE REVIEW}

\subsection{Definition of Creativity}

Creativity is the result of a mutually beneficial interaction between person and environment, interaction which needs autonomy and resistance to excessive social control. Associated to creativity are aspects of cognitive skills, personality traits, motivation, learning style, strategy, decision making, thought management, amongst others. Creativity is a psychosocial ocurrance, expression of characteristics both of the individual and the social environment or ecosystem (Alencar 2010). In other words, an individual's creative thoughts are consequences of the environment they are found in as well. 


\subsection{Developing Creativity}

The experiment led by Azevedo et al. (2017) with the Future Problem Solving Program International had positive results. All competencies showed significant increase on the experimental group. This indicates a promising possibility of developing creative thought.

Moffat and Shabalina (2016) studied the relationship between imposed restrictions on the solution of a task and the levels of creativity reached in finding a solution to the desk. It should be noted that a game with the purpose of aiding the development of creative thought on the player should present challenges with some form of constraint or rule so that the player has some guidance on how to practice their creativity. That said, it is important that the game is not so strict as to limit the player's freedom in pursuing their ideas and keeping them from engaging their creativity.

An individual may reach a more creative solution by spending a longer time thinking about the task (Zhang 2014). On the other hand, an overly long session of creative thinking may lead to cognitive exhaustion and unsatisfactory results (Coppi 2015), influencing the ability to focus on a specific task. It seems that minimum amount of time a player must engage with a game designed to aid the development of creative thought must be intentional and calculated.

A superior's feedback has a positive impact on an employees' ability to engage in creative thought, but that depends largely on the employee's capacity to monitor themselves (Zhou 2013). The impact is more significantly positive when the employee practices self-monitoring. When aiding the development of creative thought, it is important not only to give constructive feedback, but also stimulate self critique.

A player's final experience with a game is influenced by their age. Vella et al. (2013) conducted a study with people with ages ranging from 12 to 52 years. They found a positive relation between age and the player's feelings wellbeing. Therefore, the same game will have a different effect on different aged players (Vella 2013). It would be unlikely to design a game that had equally satisfactory results spanning all age groups.

\subsection{Measuring Creativity}

There are multiple tools to measure creative thought. The most famous is possibly the Torrance Tests for Creative Thinking, on which was based the Abbreviated Torrance Test for Adults. The TTCT is well trusted and often mentioned when talking about measuring creativity (Cramond 2005).

Besides the TTCT and the ATTA there is also the Abedi Test for Creativity, what is a self-evaluation test, making it useful as a way to understand an individual's own self perceived ability to think creatively. The test created by Alencar et al. (2010) is also self-evaluative, with the advantage of being designed in the language spoken by the experimental group studied in this research.

\section{METHOD}

Luovus was made in JavaScript (using the PixiJS graphical engine) and considering the ease of accessing a web page and multiplatform application. Modules are added to the main .html page of the game. Modules are activated and deactivated as needed. Each module corresponds to a questionnaire, a scene or a menu screen. To manage the modules, an engine called Voorhees was written in JavaScript (Figure 1). This engine initializes PixiJS and decides which modules will be activated and deactivated based on game states.



Figure 1. Functioning of the Voorhees engine 
When a scene module is loaded, Voorhees load a corresponding.json file containing the scene information, like appearing characters, dialogue and background art. Voorhees then interprets this information and, working in tandem with PixiJS, draws the scene on the screen. Then, Voorhees interprets player interactions and reacts accordingly.

When the game is first accessed the user is presented with the main screen, containing the options "start" and "about". Upon choosing "start" the user is asked to answer the self-evaluative creativeness questionnaire created by Alencar et al. (2010) (Figure 2). Since the game will be tested with portuguese speakers, this specific test was chosen for being written originally in portuguese. The questionnaire consists of 66 questions in the format "I would be more creative if..." followed by a statement. For instance "I would be more creative if I were less afraid to share my ideas". For each statement the user must inform if they "completely disagree", "partially disagree", are "undecided", "partially agree" or "completely agree". The results are analyzed on a Likert Scale. The questionnaires purpose is to understand how the user perceives their own creativity in a self-evaluation. According to Zhou (2013), as important as giving positive feedback to the player is, it is also important to lead the player into monitoring their own creative engagement and find ways to further develop their own creativity.

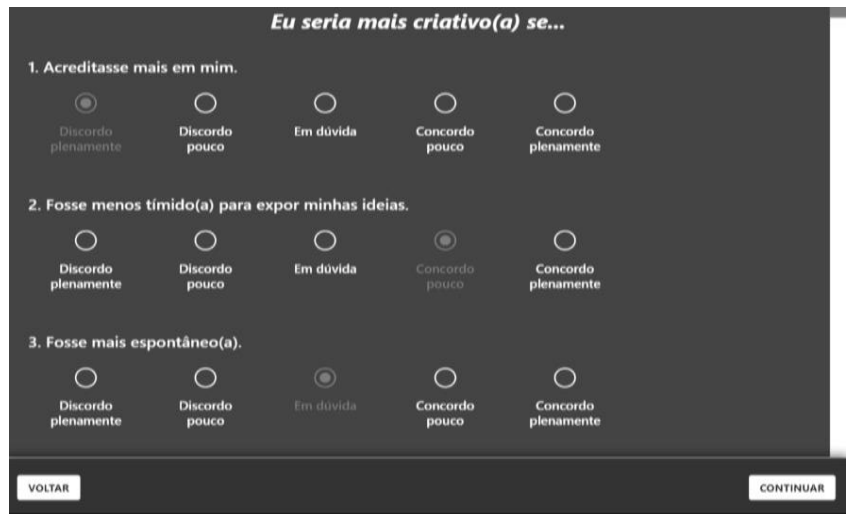

Figure 2. Likert Scale with translation of questions and metric ( "I would be more creative if... 1. I believed more in myself. 2. I were less afraid to share my ideas. 3. I were more spontaneous.") The scale used was "Completely disagree Partially disagree | Undecided | Partially agree | Completely agree"

After the questionnaire, the player is taken to the game. At a first moment the player is presented to the Artist, a character that will serve as a guide to the player during the game. After the Artist explains the story of the game to the player, a second character appears. This character will be the first amongst others to ask the player for help (Figure 3a). In this first instance it is made clear to the player they are welcome to respond in the most outlandish way possible. Shortly after, in the same scene, the player's response is reacted to by the characters present, so as to show the player that the game world will react to their choices.
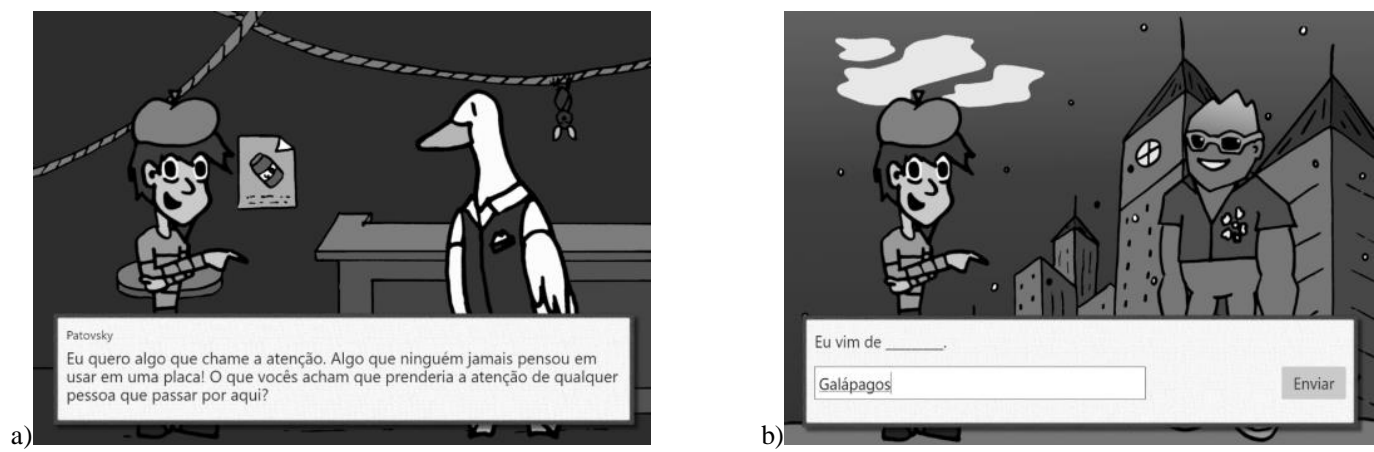

Figure 3. a) "(...) What do you think would grab the attention of anyone who came through here?"; b) "I come from"

Throughout the game the player will meet other characters with whom they will interact (Figure 3b). At each interaction the player is presented with the opportunity to come up with a solution to a problem. At the end, the Artist will present the player a story he wrote. This story changes based on the interactions the player had with the world. 
After the game, the player is asked to answer the questionnaire again. This is done to analyze the impact the game had in the player's perception of their own creativity, besides their approach to each question in the questionnaire. The results of the questionnaires answered by the players are saved on a .json file without any information that might compromise the player's anonymity. Each file is identified by a unique random id.

\section{RESULTS}

The sample group comprises of 7 male participants and 8 female participants, for a total of 15 participants. Participants were chosen by age group and degree of academic education. The youngest participant was 20 years of age and the oldest participant was 25 years of age, for an average of 22 year of age in the sample group. When comparing the results between the pretest and the post test for the creativity test, there was found no significant variation in the scores for the subjects perceived creativity, with an average variation of -6 on a scale of -132 to 132 (Figure 4).

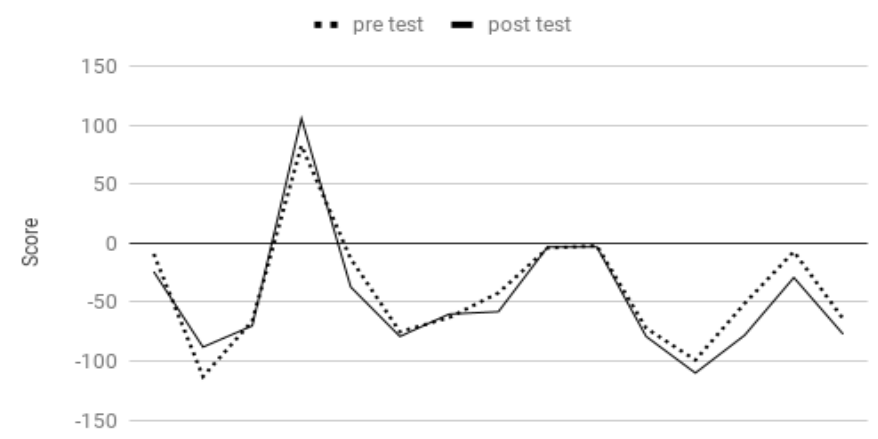

Figure 4. Score variation on the creativity test between the pretest and the post test for each player

The variation on the answers for each question between the pretest and the post test was also analyzed (Figure 5). In other words, if the subjects scored higher or lower on each given question on the post test in relation to the pretest.



Figure 5. Average score variation for each question of the creativity test between the pretest and the post test

Most questions showed no relevant variation in their scores, with a variation of 5 points or less. Some questions, on the other hand, showed a more relevant variation, variating up to 10 points, namely questions 9 , $10,30,41,43,48,53,60$ and 66 .

Table 1. Questions on the creativity test with the most relevant score variation

\begin{tabular}{lll}
\hline Question & "I would be more creative if.." & Variation \\
\hline 9 & "I had more initiative" & 10 \\
10 & "I wasn't afraid of contradicting people" & -8 \\
30 & "I wasn't afraid of being misunderstood" & -9 \\
41 & "I had more resources to put my ideas into practice" & 7 \\
43 & "I hadn't been put down by my teachers" & -6 \\
48 & "There was more cooperation between people" & -8 \\
53 & "People valued more new ideas" & -8 \\
60 & "I had a sense of humor" & -7 \\
66 & "I had more knowledge" & 9 \\
\hline
\end{tabular}




\section{CONCLUSION}

When asked about their experience with the game, 11 of the players reported having found the game "fun", "pleasant" or "interesting", which indicates that over two thirds of the subjects reported having a positive experience interacting with the game. Additionally, five of the subjects reported that they found the game too short, which could possibly aid the player in reaching a state of flow. It is possible the results would be more enlightening if the game was longer.

Analysis of the results does not indicate that game has aided in developing the players' creative thought. As the test is of the self-evaluating kind, it is possible the negative average score variation is due to the players evaluating themselves more criteriously after having played the game. In other words, roughly half the participants complained that the test is too long. This would be similar to the problem found by Coppi (2015), in which it's duration affected negatively the results. A test reduced in size or integrated seamlessly with the game could have mitigated this effect, and this might be further investigated in future research with more users and application of telemetry of the game combined with neural networks to explore how different they are.

While the average variation of the results for each individual question has been, for the most part, insignificant, it is interesting to note the questions that had an average variation of over 5 points. When looking at positive and negative variation, it is possible to speculate that the game had the effect on the players of giving them some confidence in not needing outside material and intellectual resources to be creative, but less confident in how others and society would react to their ideas. Questions such as "I would be more creative if I had more initiative" and "I would be more creative if I had more knowledge" had a notably positive variation, which may signal that the experience of practicing their creative skills made the players feel more confident in their capability of producing creative ideas without the need of outside assistance.

\section{REFERENCES}

Ahmadi, G. A.; Abdolmaleki, S.; Khoshbakht, M. 2011. Effect of computer-based training to increase creativity and achievement science, students in fourth grade of elementary. In Procedia Computer Science, pp. 1551-1554.

Alencar, E. M. L. S.; Fleith, D. S.; Bruno-Faria, M. F, 2010. A Medida da Criatividade: Teoria e Prática. Artmed, Porto Alegre, Brazil.

Azevedo, I.; Morais, M. D. F.; Martins, F. 2017. Educação para a Criatividade em Adolescentes: Uma Experiência com Future Problem Solving Program International. In REICE, pp.75-87.

Buzady, Z. 2017. Flow, leadership and serious games - a pedagogical perspective. In World Journal of Science, Technology and Sustainable Development, Vol. 14 Issue: 2/3, pp.204-217.

Coppi, A. E. 2015. Fostering creativity through games and digital story telling. 2015 International Conference on Interactive Technologies and Games, Nottingham, England, pp. 17-21.

Li, Zhang; Qiong, Bu; Wee, Sooyeon. 2014. Impact of Job Control on Employee Creativity: The Moderating Effect of Cognitive Irritation. Proceedings of the 21 th ICMSEM , Helsinki, Finland, pp.873-878.

Maslow, A. H. 1943. A Theory of Human Motivation. In Psychological Review, pp. 430-437.

Moffat, David C.; Shabalina, Olga. 2016. Student Creativity Exercises in Designing Serious Games. European Conference on Games Based Learning, Paisley, Scotland, pp.470-478.

Vella, Kellie; Johnson, Daniel; Hides, Leanne. 2013. Positively playful: When videogames lead to player wellbeing. Proceedings of the Gamification 2013, Stratford, Canada, pp. 99-102.

Wang, Kai. 2013. The Effect of Autonomy on Team Creativity and the Moderating Variables. 2013 Proceedings of PICMET '13: Technology Management for Emerging Technologies, San Jose, USA, pp.1156-1160.

Zhou, Ming-Jian; Li, Shu-Kun. 2013. Can Supervisor Feedback always Promote Creativity? The Moderating Role of Employee Self-Monitoring. Proceedings of the ICIII 2013, Shenzhen, China, pp.510-512. 